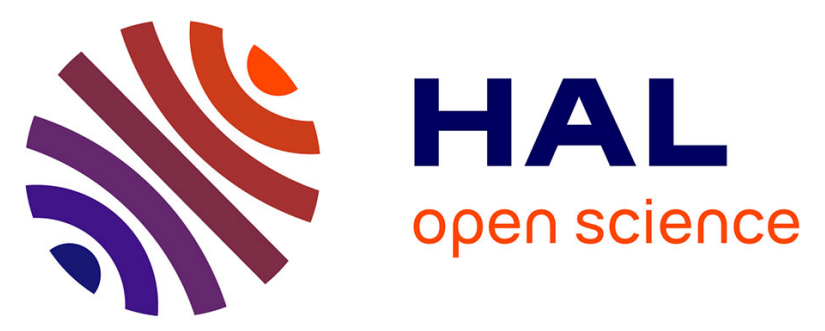

\title{
Combustor and Material Integration for high speed aircraft in the European research Program ATLLAS2.
}

Marc Bouchez, F. Crampon, Bruno Le Naour, C. Wilhelmi, K. Bubenheim, M. Kuhn, B. Mainzer, J. Riccius, C. Davoine, J.F. Justin, et al.

\section{- To cite this version:}

Marc Bouchez, F. Crampon, Bruno Le Naour, C. Wilhelmi, K. Bubenheim, et al.. Combustor and Material Integration for high speed aircraft in the European research Program ATLLAS2.. 19th AIAA International Space Planes and Hypersonic Systems and Technologies Conference, Jun 2014, ATLANTA, United States. hal-01069248

\section{HAL Id: hal-01069248 \\ https://hal-onera.archives-ouvertes.fr/hal-01069248}

Submitted on 29 Sep 2014

HAL is a multi-disciplinary open access archive for the deposit and dissemination of scientific research documents, whether they are published or not. The documents may come from teaching and research institutions in France or abroad, or from public or private research centers.
L'archive ouverte pluridisciplinaire HAL, est destinée au dépôt et à la diffusion de documents scientifiques de niveau recherche, publiés ou non, émanant des établissements d'enseignement et de recherche français ou étrangers, des laboratoires publics ou privés. 


\title{
Combustor and Material Integration for High Speed Aircraft in the European Research Program ATLLAS2.
}

\author{
Marc Bouchez ${ }^{1}$, Fréderic Crampon ${ }^{2}$, Bruno Le Naour ${ }^{3}$ \\ MBDA, rond point Hanriot, 18020 Bourges, France \\ Christian Wilhelmi ${ }^{4}$, Kai Bubenheim ${ }^{5}$ \\ AIRBUS Group Innovations, Ottobrunn, Germany \\ Markus Kuhn ${ }^{6}$, Bernd Mainzer ${ }^{7}$ \\ German Aerospace Center (DLR), 70569 Stuttgart, Germany \\ Jörg Riccius ${ }^{8}$, \\ German Aerospace Center (DLR), 74239 Hardthausen, Germany \\ Cecile Davoine ${ }^{9}$, Jean-Francois Justin ${ }^{10}$ \\ ONERA, The French Aerospace Lab, Chatillon, France \\ Jens von Wolfersdorf ${ }^{11}$, Meriam Abdelmoula ${ }^{12}$, \\ USTUTT, University of Stuttgart, Germany \\ Victor F.Villace ${ }^{13}$, Johan Steelant ${ }^{14}$ \\ ESA, 2200 AG Noordwijk, The Netherlands
}

\begin{abstract}
Hypersonic airliner would be exposed to temperatures that are beyond the limits of classical aircraft materials. In order to handle this problem the latest developments of new materials and composite structures suitable for high temperature application need to be taken into account. The focus of the European Research program ATLLAS is on advanced light-weight, high-temperature material development strongly linked to a high-speed passenger aircraft design. ATLLAS stands for Aerodynamic and Thermal Load Interactions with Lightweight Advanced Materials for High Speed Flight. The 4 years program ATLLAS-II is a logical continuation project built upon the experience and technology development gained within ATLLAS-I. The corresponding work related to combustor structures and material integration deals with the opportunity to investigate at academic level, both in basic and relevant environment, different solutions possibly usable to ensure the long range cruise of a high speed airliner. Different materials (UTHC, CMC, metallic) and different cooling techniques (radiation, convective, transpiration) are studied. Available numerical or semi-empirical tools are used to prepare the test, to design the different architectures. A pin fin experiment allows to better know the pressure drop and the heat transfer for different channel patterns with thermal cristal techniques. The ERBURIG ${ }^{\mathrm{K}}$ long
\end{abstract}

${ }^{1}$ Aerospace Engineer, AAAF Senior Fellow, AIAA Member

${ }^{2}$ Mechanical and thermal ground testing

${ }^{3}$ Aerospace Engineer, AAAF Member, AIAA Member

${ }_{5}^{4}$ Project Engineer, Airbus Group Innovations (TX2), Willy-Messerschmitt-Str. 1; 81663 Munich; Germany.

${ }^{5}$ Project Engineer, Airbus Group Innovations (TX2), Willy-Messerschmitt-Str. 1; 81663 Munich; Germany.

${ }^{6}$ Research Scientist, Space Systems Integration, Institute of Structures and Design

${ }^{7}$ Research Scientist, Ceramic Composites and Structures, Institute of Structures and Design

${ }^{8}$ Research Scientist, Rocket propulsion team, Langer Grund, 74239 Hardthausen, Germany

${ }^{9}$ Research Scientist, Metallic Structures and Materials Department

${ }^{10}$ Research Scientist, Composite Structures and Materials Department

${ }^{11}$ Professor and Research Scientist, Institute of Aerospace Thermodynamics (ITLR), Universität Stuttgart, Pfaffenwaldring 31, D-70569, Germany

${ }^{12}$ Research Scientist, Institute of Aerospace Thermodynamics (ITLR), Universität Stuttgart, Pfaffenwaldring 31, D-70569, Germany

${ }^{13}$ Aerospace Engineer, Aerothermodynamics and Propulsion Analysis Section

${ }^{14}$ Senior Aerospace Engineer, Aerothermodynamics and Propulsion Analysis Section, AIAA member.

1

American Institute of Aeronautics and Astronautics 
duration test facility allow to characterize different ceramic matrix composite uncooled samples and will allow to realize, at small scale, a long duration (several hours) investigation of cooled ceramic structure in PTAH-SOCAR technology. A multifonctionnal metallic transpiration cooled HSS panel using Hollow Spheres Stacking as core material was designed and preliminary tested in cold conditions with GN2 and in hot conditions with infra red lamps under $1 \mathrm{MW} / \mathrm{m}^{2}$ heat flux. CMC and UHTC materials are used to design, manufacture and test generic fin injectors usable in high speed combustors. Industrial hypersonic METHYLE test facility is used to test in relevant Mach 6 combustor environment HSS panel as well as advanced fin injectors. Hot and cold permeability of composites is documented with GN2 and GH2. Numerical models are used in accordance with the experiments, some examples are given in the present paper.

\begin{tabular}{|c|c|}
\hline & Nomenclature \\
\hline $\mathrm{C} / \mathrm{C}-\mathrm{SiC}=$ & carbon fibre reinforced silicon carbide \\
\hline CFD & computational fluid dynamics \\
\hline $\mathrm{CMC}$ & ceramic matrix composite \\
\hline ERBURIG $^{\mathrm{K}}$ & $=$ Environmental Relevant Burner Rig - Kerosene \\
\hline HSS & Hollow Spheres Stacking (sandwich) \\
\hline $\mathrm{GN}_{2}$ & gaseous nitrogen \\
\hline METHYLE $=$ & $=$ French acronym for long duration hypersonic technology test facility \\
\hline $\mathrm{O}_{2}$ & oxygen \\
\hline $\mathrm{SiC} / \mathrm{SiCN}=$ & silicon carbide fibre reinforced silicon carbonitride \\
\hline TLC & Thermochromic Liquid Crystals \\
\hline UHTC & ultra high temperature ceramic \\
\hline USTUTT/IT & $\mathrm{R}=$ University of Stuttgart \\
\hline WHIPOX = & wound highly porous oxide \\
\hline
\end{tabular}

\section{Introduction}

For high-speed aircraft, material and cooling issues for both airframe and engine are the key elements which force the designer to limit the flight Mach number. The expected benefits of economical, high-performance and high-speed civil-aircraft designs that are being considered for the future will be realized only through the development of light-weight, high-temperature composite materials for structure and engine applications, to reduce weight, fuel consumption, and direct operating costs, as well as optimized structures and associated design methods.

The focus of the European Research program ATLLAS ${ }^{1,2}$ is on advanced light-weight, high-temperature material development strongly linked to a high-speed passenger aircraft design. ATLLAS stands for Aerodynamic

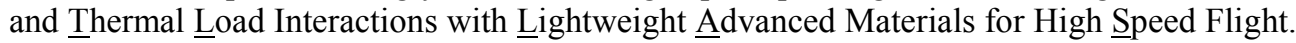

The 4 years program $A T L L A S-I I$ is a logical continuation project built upon the experience and technology development gained within ATLLAS-I.

The previous ATLLAS study revealed in the end that the optimal cruise Mach number of such an high speed airliner could be around Mach 5 to 6 . In ATLLAS2, a more detailed design and feasibility system study is performed here which aim to a globally optimized vehicle with respect to aerodynamic, propulsive, structural and thermal layout but nevertheless allowing restrictions imposed by emissions regulations and sonic boom mitigation. The validated tools developed previously along with the lessons learned allow the ATLLAS consortium (industry, research institutes and university laboratories) to further address and improve the multi-disciplinary design process of such future systems.

In parallel, a lot of effort is still foreseen to extend the precious built-up material database with durability characterization both for the aero-frame and combustor related structures. Also new materials and compositions are addressed to cope with limitations previously encountered.

A generic aircraft design for high-speed flight is then retained as a guideline in the Work Package 2 of the Program. Its cruise Mach number target is close to 6 . 
The Work Package 4 of the current Program is entitled Combustor and Material Integration and is described in the present paper. Its objective is to study material and structures for combustors and advanced hot structures while WP1 covers with project management, WP3 deals with material development and characterization and WP5 with numerical research and boundary layer transition experiments.

The work package WP4 is split up into 3 tasks dealing with:

- Task 4.1. Durability for Combustion loaded Non-Metallic Liners

4.1.1 Flat and PTAH-SOCAR axisymetric samples in long duration test in ERBURIG ${ }^{\mathrm{K}}$ test facility

4.1.2 Permeability measurements in DLR Lampoldshausen at elevated temperatures, in addition to existing ambient temperature characterization of these porous structures

4.1.3 Pin fin channel well documented in an USTUTT experiment

- Task 4.2. Durability for Combustion loaded Panels with Metallic Cores (hollow spheres)

- Task 4.3. Integration and Testing of (Un)Cooled Injectors (CMC or UHTC material)

WP4 work is connected with the other work packages of ATLLAS-2 : System studies from ATLLAS-1 and WP2 results will be used as guidelines to define the architecture and the test condition of WP4 samples.

- Material and structures for combustors and advanced hot structures

- Solutions : materials and studies

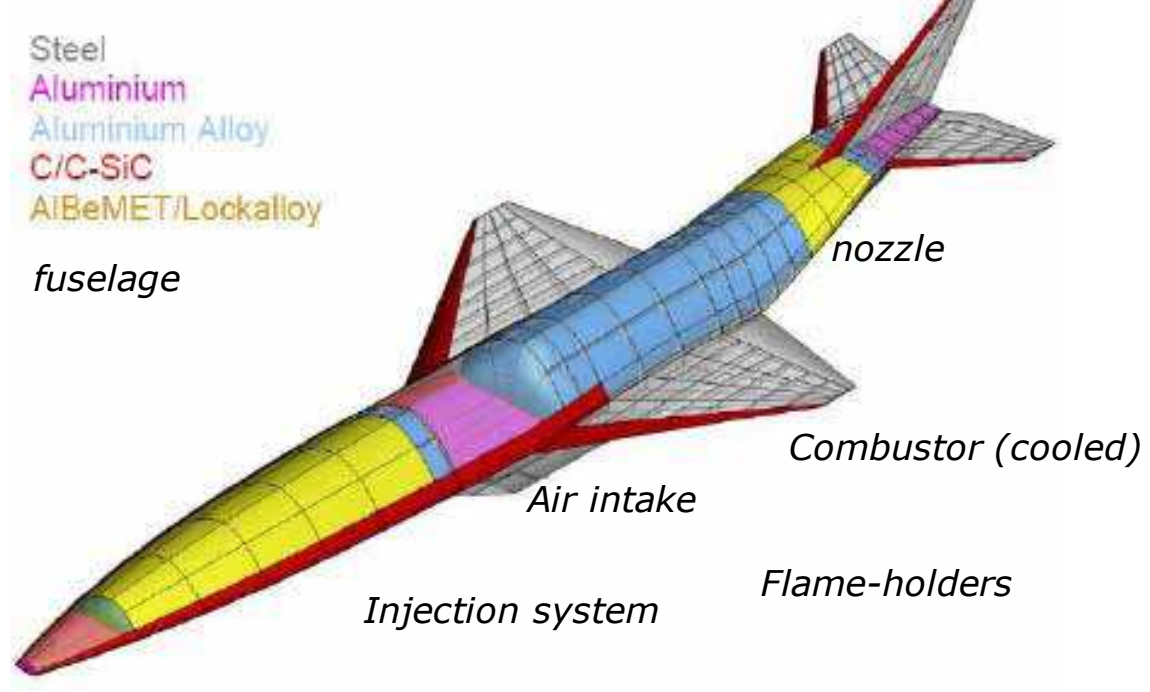

Figure 1 : system studies as a guideline for structures to be used in different sub-systems

WP4 will use the materials enhanced and characterized in WP3. WP4 will provide a data base for numerical simulations in WP5.2

WP4 material and structures investigated in WP4 will be hot tested in laboratory and later in realistic environment : long duration test in the ERBURIG ${ }^{\mathrm{K}}$ test facility at Airbus Group Innovations ${ }^{6}$ in Ottobrunn (Germany) and industrial METHYLE dual-mode ramjet test facility ${ }^{7}$ at MBDA Bourges (France). 


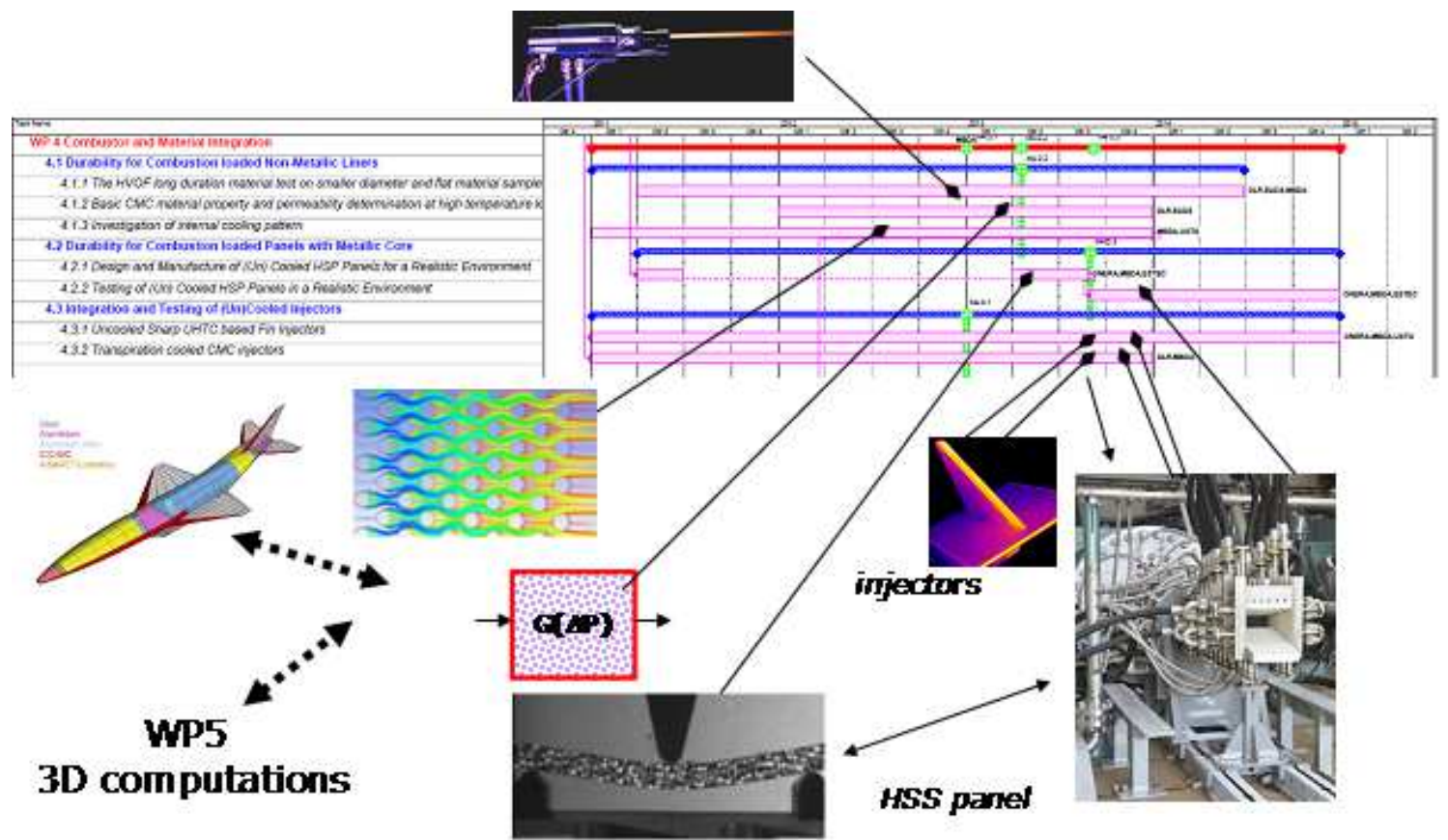

Figure 2 : Gantt chart and main test and interaction of WP4 in ATLLAS2 program

\section{Pin fin experiment}

A ten times scaled Perspex channel is set at Stuttgart University to investigate in details pin fin channels with staggered configurations. The test rig is working under suction mode and is connected to a vacuum pump. An electrical mesh heater is used to generate a step change in the thermal boundary condition to achieve a significant and nearly constant fluid temperature jump. A schematic view of the test facility is shown in Figure 3.

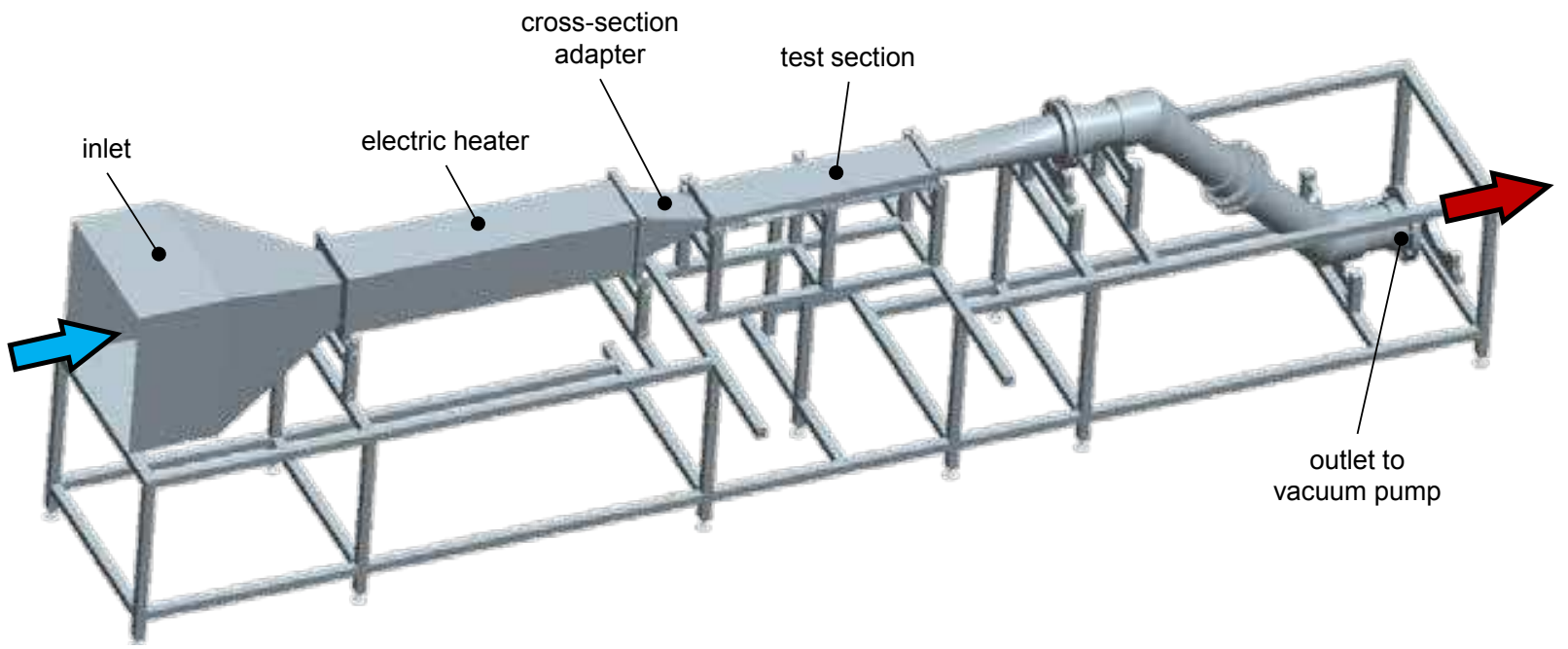

Figure 3 : Schematic view of the test facility in Stuttgart University

Three different staggered pin fin configurations are experimentally and numerically investigated. 


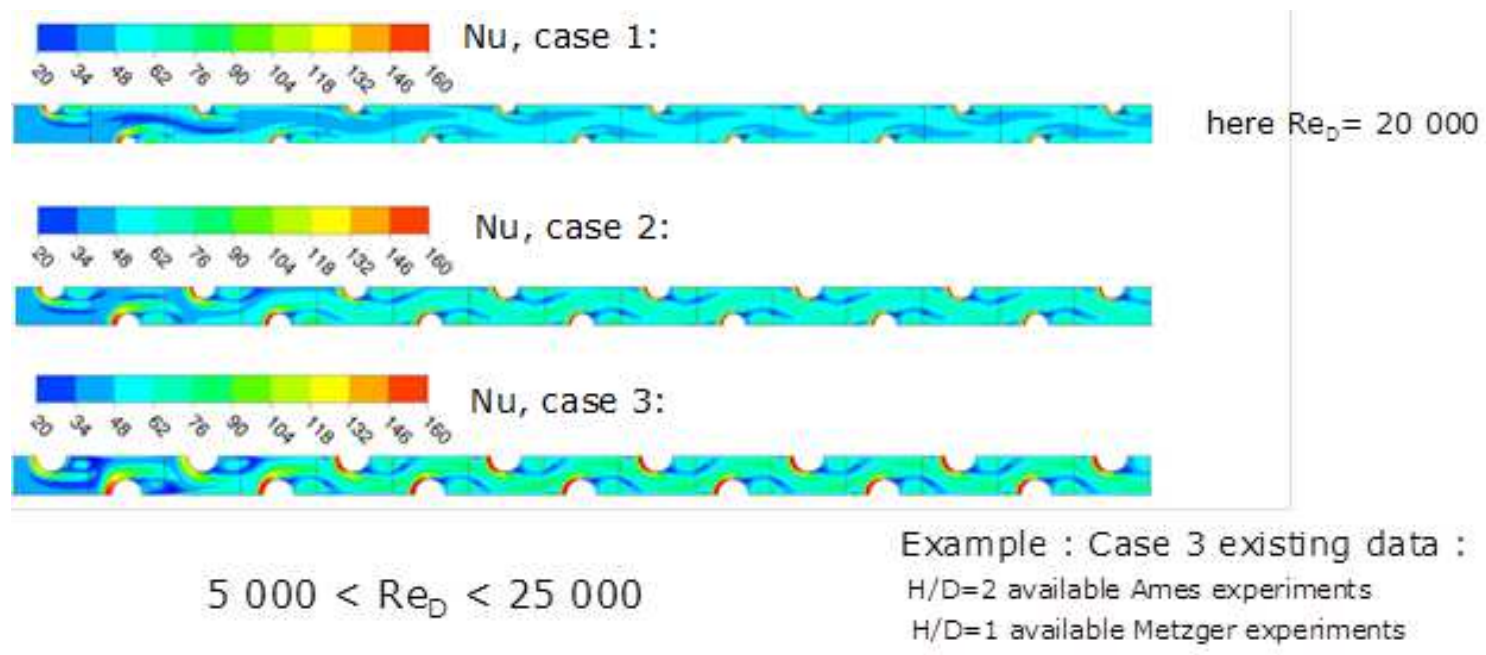

Figure 4 : different pin fin pattern studied (here CFD results) within warm air experiment

The main differences between these arrays are the relative span wise and stream wise spacing and the relative height. This parameter variation is achieved by changing the pin diameter. These test cases are summarized in table 1 and in Figure 4, showing preliminary CFD computations of the corresponding flows depending on flow pattern.

\begin{tabular}{|l|c|c|}
\hline Case name & D $[\mathbf{m m}]$ pin fin diameter & H/D : channel height relative to pin fin diameter \\
\hline Case 1 & $\mathbf{8}$ & $\mathbf{4}$ \\
\hline Case 2 & $\mathbf{1 2}$ & $\mathbf{2 . 6 7}$ \\
\hline Case 3 & $\mathbf{1 6}$ & $\mathbf{2}$ \\
\hline
\end{tabular}

Tab. 1: Pin fin diameters and non-dimensional parameters of investigated cases

The heat transfer enhancement thanks to the pin fin arrays has as penalty a total pressure loss.

The integral pressure drop is evaluated. Therefore the test section is instrumented with twenty two pressure tubes at the side wall as sketched in Figure 5. These pressure taps measure the static pressure, which corresponds to the total pressure at the wall. A differential pressure measuring system is used.
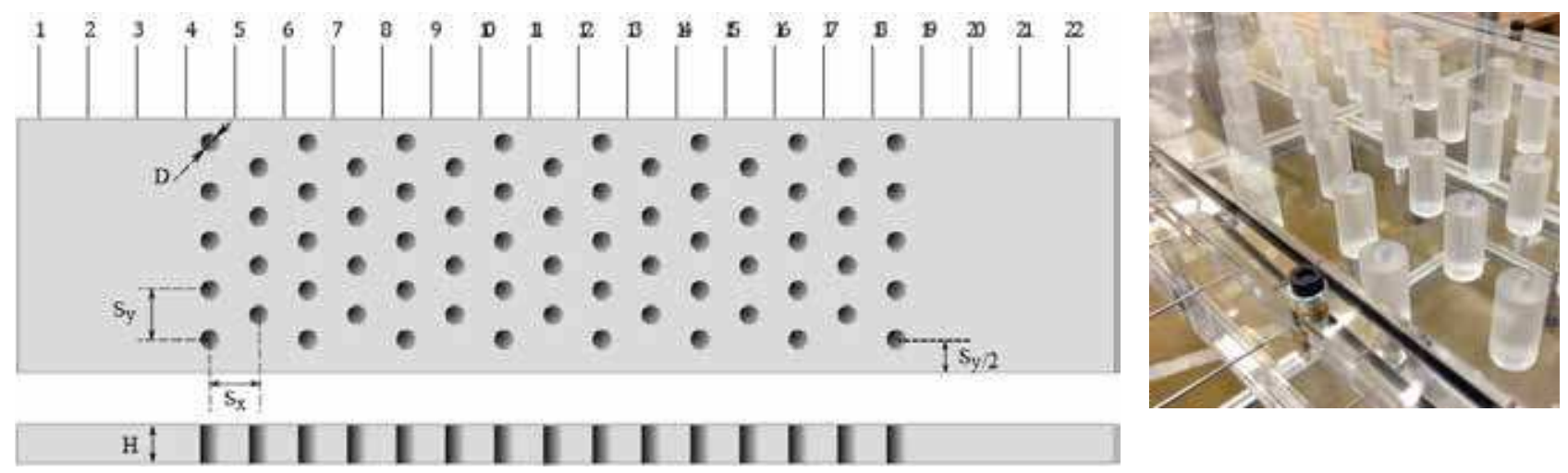

Figure 5 : Staggered pin fin array pattern and photograph of the test section

An example of the pressure distribution across the pin fin array is depicted in Figure 6 for different Reynolds numbers for Case 2. The pressure distribution is marked by likely constant values at the inlet (positions 1 to 3 ) and outlet (positions 20 to 22) sections. The flow is experiencing alternatively deceleration at the stagnation region and 
acceleration in the pin fin wake. This is demonstrated with the echelon form of the pressure distribution between the pin fin rows. The higher the Reynolds number, the lower is the pressure level in the test section.

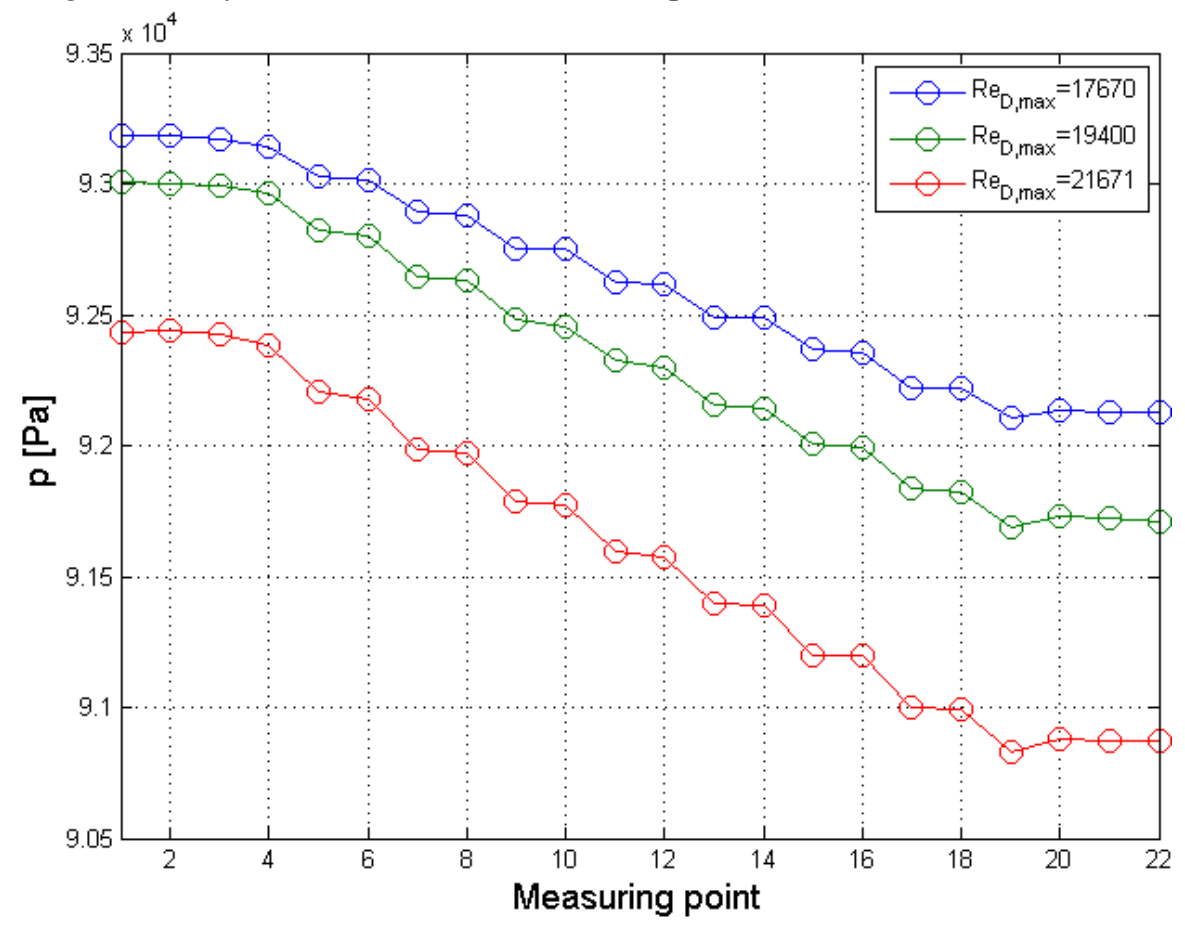

Figure 6: Pressure distribution at the side wall of the pin fin array, Case 2

The pressure loss can be quantified in terms of a dimensionless number, called friction factor and introduced with the following formula:

$$
f=\frac{\Delta p}{2 \rho u_{\max }^{2} N}
$$

The pressure loss $\Delta p$ over $N$ rows is calculated from the linear regression between the measuring points 4 and 19. Consequently inlet and exit recovery effects are disregarded. The maximum averaged velocity $u_{\max }$ is determined between two pin fins and is obtained according to the mass conservation law from the approach flow velocity and the specific configuration. The same velocity is used to determine the Reynolds number based on the pin diameter as characteristic length. The measurements are compared with the correlation of Jacob ${ }^{4}$, that is valid for $H / D \geq 2$ in the investigated Reynolds number range. This empirical relation is in good agreement with the experimental data as shown in Figure 7.

$$
f=\left(0.25+\frac{0.1175}{\left(\frac{S_{y}}{D}-1\right)^{1.08}}\right) R e_{D, \text { max }}^{-0.16}
$$




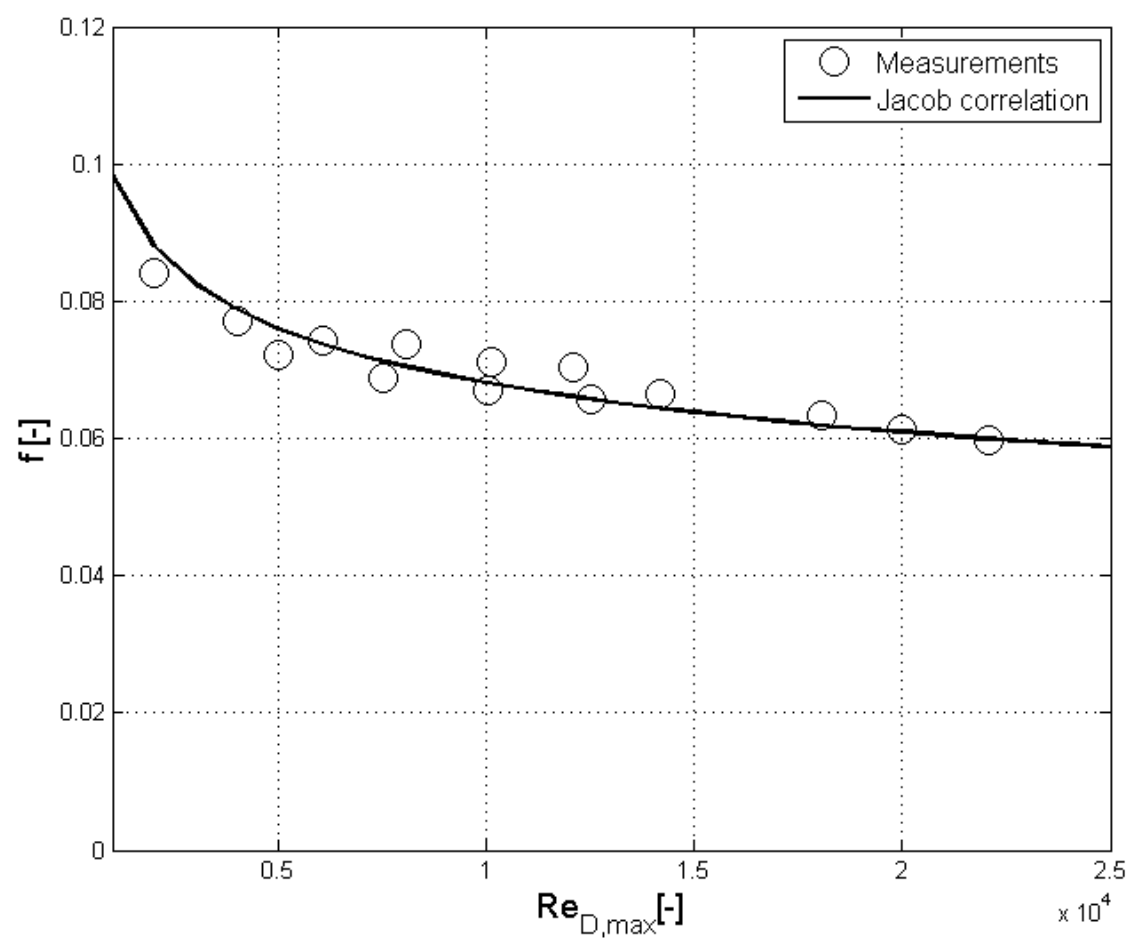

Figure 7: Validation of friction factor versus Jacob correlation [1] for Case 2

The transient heat transfer measurement technique using Thermochromic Liquid Crystals (TLCs) on the Perspex walls is used to measure the heat transfer at the end wall. The lateral conduction is neglected due to the relatively short measurement time and the low thermal conductivity of the used Perspex material. The conduction process into the wall can then be considered one-dimensional and the wall analytical treated as being semi-infinite for the conduction process during the measurement period.

The transient measurement technique provides accurate two dimensional heat transfer distributions. The experiments start at the equilibrium state, in which the complete test section is initiated at a constant uniform temperature. The transient technique examines the response of the wall temperature to a sudden change in the fluid temperature. An abrupt temperature rise of the main stream is generated with the mesh heater so that temperature gradients between the fluid and the wall arise. The surface temperature is monitored using TLCs. The green color stands for the calibrated indication temperature and is tracked by a high resolution CCD camera.

An analytical 1D-solution of Fourier's heat conduction equation for the solid wall (index $s$ ) describes the time response of the surface temperature for a semi-infinite wall:

$$
\frac{\partial T_{s}}{\partial t}=\frac{k_{s}}{\rho_{s} c_{s}} \frac{\partial^{2} T_{s}}{\partial y^{2}}
$$

The material properties are assumed to be constant. The differential equation is then solved with the following initial and boundary conditions:

$$
\begin{gathered}
t=0: T_{s}=T_{0}, \quad y \longrightarrow \infty: T_{s}=T_{0} \\
y=0:-k_{s}\left(\frac{\partial T_{s}}{\partial y}\right)=h\left(T_{w}-T_{f}\right)
\end{gathered}
$$

The surface is represented with $y=0$ and $h$ refers to the local heat transfer coefficient. 
By assuming a semi-infinite wall with a convective boundary condition, constant material properties, constant local heat transfer coefficient $h$, negligible lateral conduction effects and for an ideal fluid temperature step, the solution for the surface temperature $T_{w}(t)$ at the end wall is obtained as:

$$
\frac{T_{w}(t)-T_{0}}{T_{f}-T_{0}}=1-\exp \left(\frac{h^{2} t}{\rho_{s} c_{s} k_{s}}\right) \operatorname{erfc}\left(\frac{h \sqrt{t}}{\sqrt{\rho_{s} c_{s} k_{s}}}\right)
$$

The reference fluid temperature $T_{f}$ is chosen to be the fluid bulk temperature. Duhamel's superposition principle is applied to account for variations compared to an ideal temperature step especially at down-stream positions due to the upstream heat exchange. The local fluid bulk temperature history is therefore approximated by many small ideal temperature steps $\Delta T_{f(j, j-1)}$ between two consecutive time steps $\tau_{j-1}$ and $\tau_{j}$.

$$
T_{w}(t)-T_{0}=\sum_{j=1}^{N}\left[1-\exp \left(\beta^{2}\right) \operatorname{erfc}(\beta)\right] \Delta T_{f(j, j-1)} \text { with } \beta=h \sqrt{\frac{t-\tau_{j}}{\rho_{s} c_{s} k_{s}}}
$$

In equation (7) all variables are known or measured except for the heat transfer coefficient $h$. The USTUTT/ITLR in-house code "ProTeIn" solves the equation (7) iteratively and a detailed two dimensional heat transfer distribution is then obtained. The evaluation technique applied in this work is explained in detail in ${ }^{5}$.

An example for the distribution of the local heat transfer coefficient on the end wall is illustrated in Figure 8. This contour plot provides evidence that the horseshoe vortex contributes significantly to the end wall heat transfer in pin fin arrays. In the first and second rows, the horseshoe vortices are less developed and their footprint can be barely distinguished. The overall local distribution of the heat transfer coefficient is quite symmetric and homogenous. The third to the fifth pin fin rows play a crucial role in the heat transfer enhancement. Remaining cases are analogically investigated for different Reynolds numbers and inlet conditions.

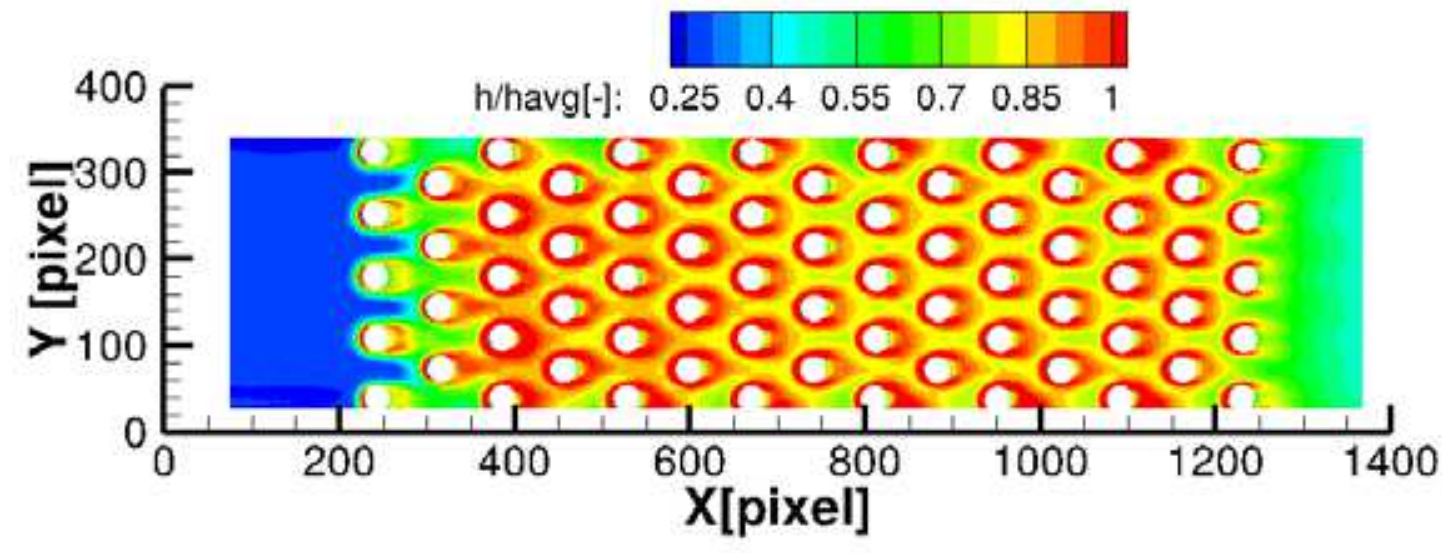

Figure 8 : Two dimensional local distribution of the normalized measured heat transfer coefficient, Case2, $\operatorname{Re}_{\mathrm{D}, \max }=\mathbf{2 5 0 0 0}$

\section{Flat sample long duration testing of CMC materials}

Flat sample testing is performed at the ERBURIG ${ }^{\mathrm{K}}$ test facility of Airbus Group Innovations in Ottobrunn (Germany) ${ }^{6}$. The test facility uses a combustion of kerosene with oxygen $\left(\mathrm{O}_{2}\right)$ to generate a hot gas comparable in temperature, composition and velocity to actual rocket combustion chamber atmospheres. 


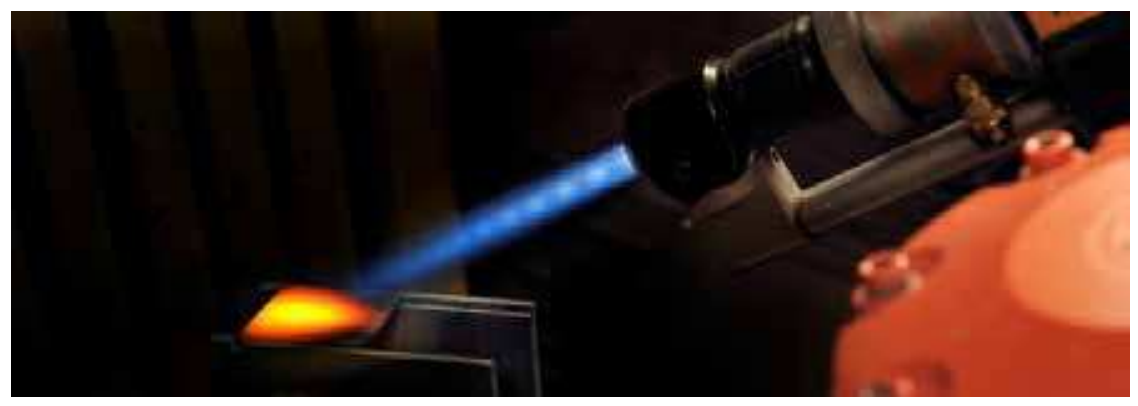

Figure 9 : flat sample testing at ERBURIG ${ }^{\mathrm{K}}$ test facility at Airbus Group Innovations, Ottobrunn (Germany)

The temperature range for the $\mathrm{CMC}$ flat samples is $1050^{\circ} \mathrm{C}-1700^{\circ} \mathrm{C}$ (measured in the hottest area using a pyrometer). The test duration varies between "short" term testing ( 1 hour) and "long" term testing ( 4 hours), split in 30 minute intervals for evaluation. During testing the samples undergo optical and weight evaluation after every interval (Figure 10). Once a major deterioration is visible (before the end of the planned test duration), the test is stopped for metallographic investigation.
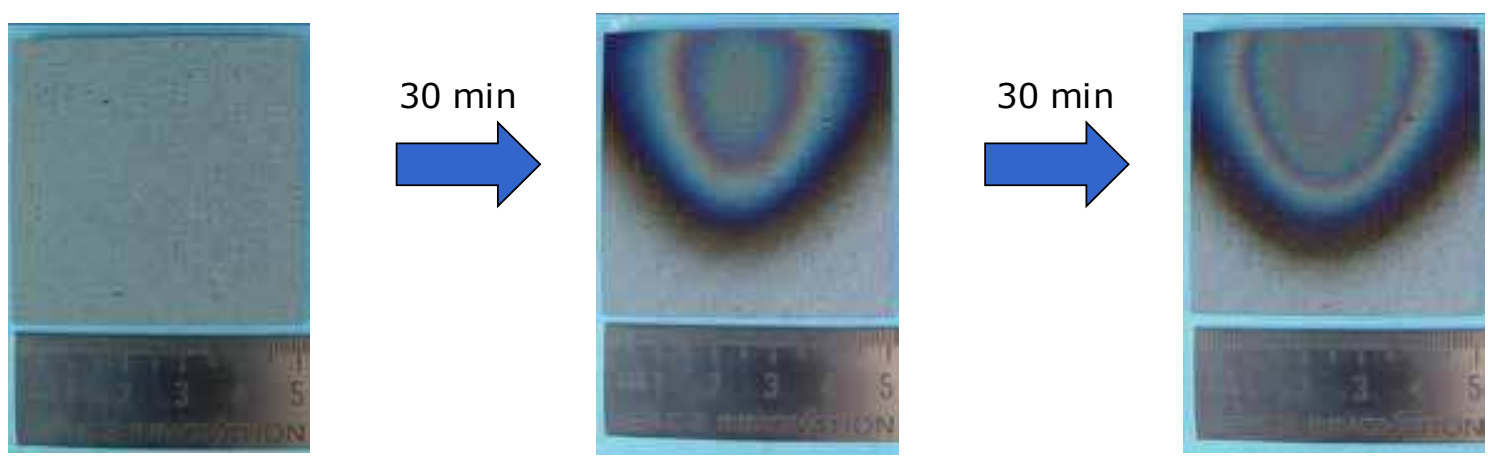

Figure 10 : example of CMC (C/C-SiC with CVD-SiC coating) test sample tested at ERBURIG ${ }^{\mathrm{K}}$ test facility

Several ceramic matrix composites from DLR and Airbus Group Innovations have been considered for ERBURIG $^{\mathrm{K}}$ testing to check their performance at high temperature in an oxidative environment. As DLR materials, $\mathrm{C} / \mathrm{C}-\mathrm{SiC}$ (with and without $\mathrm{CVD}-\mathrm{SiC}$ coating), $\mathrm{SiC} / \mathrm{SiCN}$ (in two fibre-coated variants) and WHIPOX (in two coated variants) have been investigated.

For $\mathrm{SiC} / \mathrm{SiCN}$ composites, pyrolytic carbon $(\mathrm{PyC})$ and monazite $\left(\mathrm{LaPO}_{4}\right)$ were chosen as interface material; they were "long" term tested at temperatures of 1300,1500 and $1700^{\circ} \mathrm{C}$. In general, the samples with PyC-coated fibres showed higher mass losses due to active oxidation of the coating. SEM pictures indicated that this behavior already occurred at $1300{ }^{\circ} \mathrm{C}$. The thereby emerged gaps between fibres and $\mathrm{SiCN}$-Matrix were filled with $\mathrm{SiO}_{2}$ due to an oxidation of the $\mathrm{SiC} / \mathrm{SiCN}$ system (Figure 11). This behaviour is strongly depending on exposed temperature levels and distances from the outer sample surface. At $1500^{\circ} \mathrm{C}$ and above, the coating was completely removed and filled with $\mathrm{SiO}_{2}$. In case of the $\mathrm{LaPO}_{4}$-coated fibre composites, the coating close to the surface already started to degrade at $1300^{\circ} \mathrm{C}$ and $\mathrm{SiO}_{2}$ scale could be observed between fibres and coating. As depicted in Figure 12, the entire $\mathrm{LaPO}_{4}$ coating was degraded at $1700^{\circ} \mathrm{C}$. At the center of the samples however, the coating stayed intact (Figure 13). $\mathrm{X}$-ray diffraction showed a formation of $\mathrm{La}_{2} \mathrm{Si}_{2} \mathrm{O}_{7}$ and $\mathrm{SiO}_{2}$ at the sample surfaces at temperatures of $1500^{\circ} \mathrm{C}$ and above, forming a cracked, mixed scale (Figure 14). 


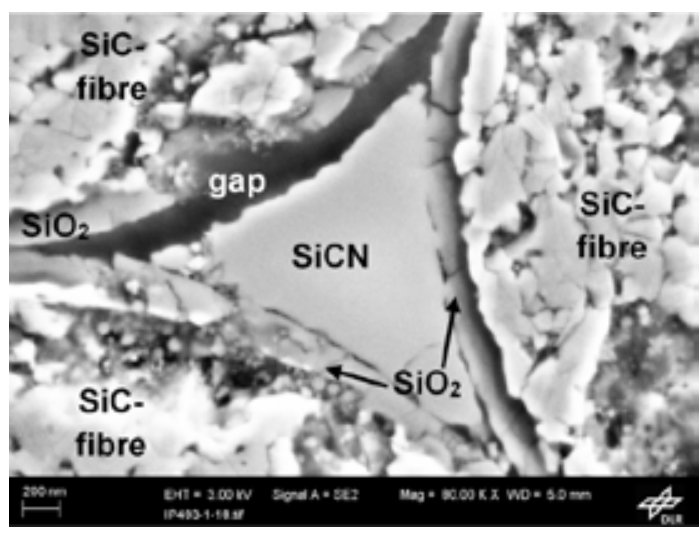

Figure 11: PyC-coated fibre sample, tested at $1300^{\circ} \mathrm{C}$, center of the sample; the PyC coating was removed due to active oxidation

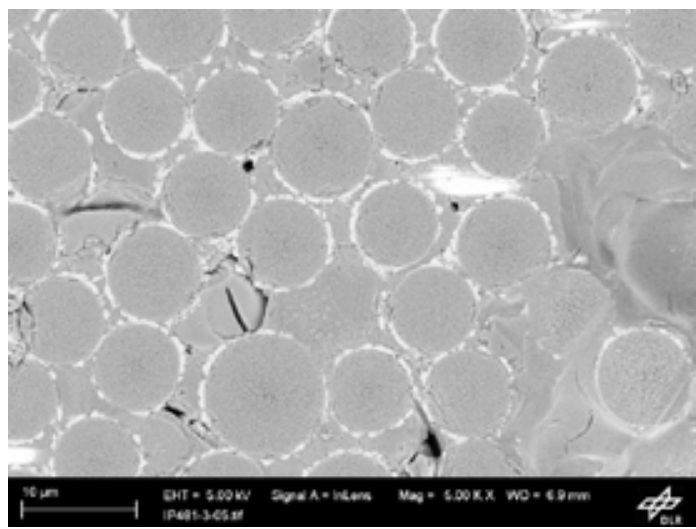

Figure 13: $\mathrm{LaPO}_{4}$-coated fibre sample, tested at $1700^{\circ} \mathrm{C}$, center of the sample

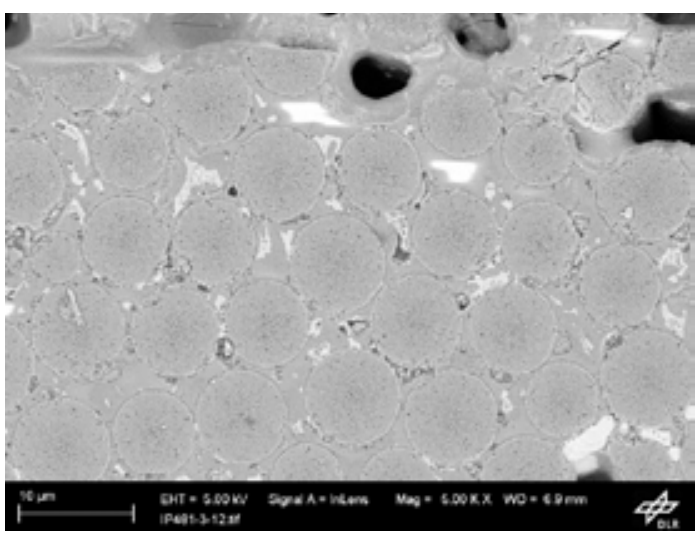

Figure 12: $\mathrm{LaPO}_{4}$-coated fibre sample, tested at $1700^{\circ} \mathrm{C}$, close to surface

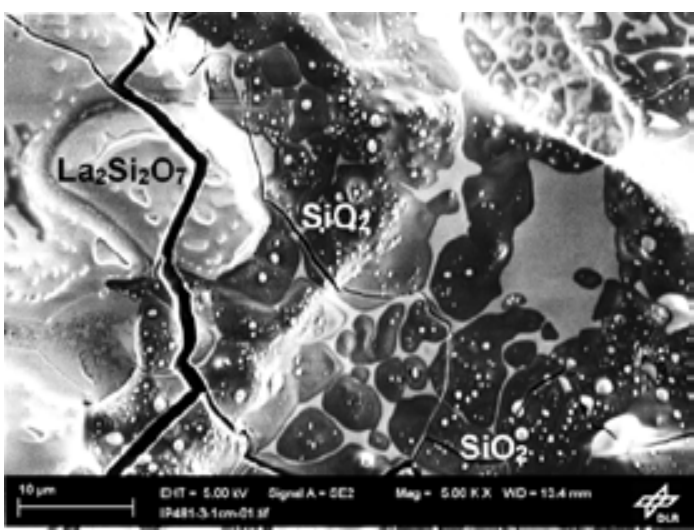

Figure 14: $\mathrm{LaPO}_{4}$-coated fibre sample, tested at $1700^{\circ} \mathrm{C}$, top view showing $\mathrm{SiO}_{2}$ and $\mathrm{La}_{2} \mathrm{Si}_{2} \mathrm{O}_{7}$ phases

An example of preliminary computation of the ERBURIG ${ }^{\mathrm{K}}$ test on a generic flat sample by ESA/ESTEC is shown below. The commercial code CFD-ACE is used in these current calculations. The SST k- $\Omega$ turbulence model is considered here as the best tradeoff between solution accuracy and computational effort and therefore remains as the chosen model for the computations. A laminar simulation of the ERBURIG ${ }^{\mathrm{K}}$ test conditions has been performed so far, in Figure 15. This solution serves as baseline for comparison with the turbulent calculations and also to initialize the turbulent simulations. The achievement of a turbulent simulation of the flow field in the ERBURIG ${ }^{\mathrm{K}}$ facility is an ongoing work. The final goal will be to compare the available measurements with the corresponding computed data. 

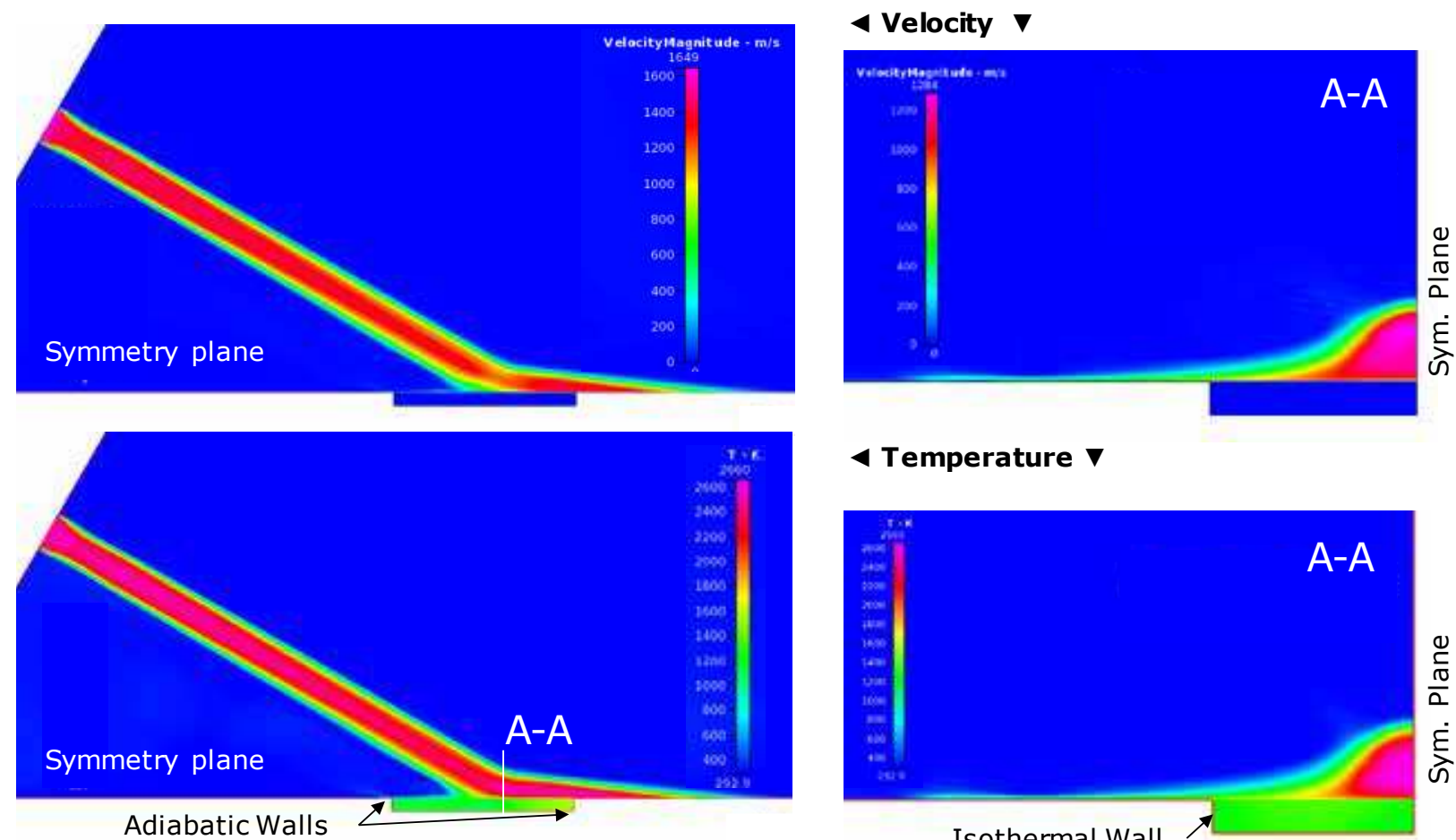

4 Temperature $\nabla$

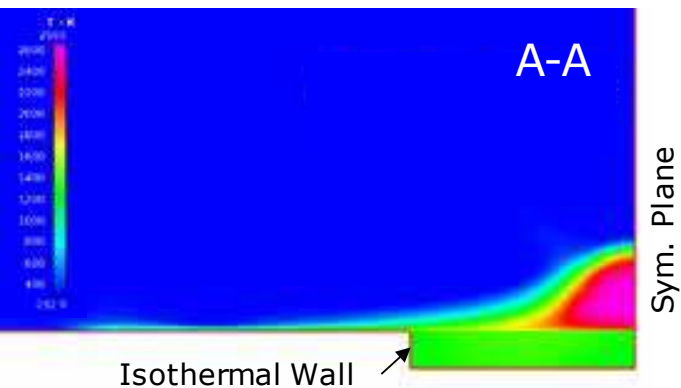

Figure 15. Example of preliminary 3D CFD simulation of the ERBURIG ${ }^{\mathrm{K}}$ test by ESTEC

\section{Elevated temperature permeability measurements with GN2 and GH2}

In addition to ambient temperature permeability measurements for $\mathrm{C} / \mathrm{C}$, OXIPOL and WHIPOX samples at DLR Lampoldshausen and other test facilities in the framework of the ATLLAS I project ${ }^{3}$, recently some $\mathrm{C} / \mathrm{C}$ and OXIPOL samples have been tested at elevated temperatures in order to later characterize the permeability (Darcy and Forchheimer coefficients) of theses samples with different fluids in the framework of the ATLLAS II project. In comparison to the previously used ambient temperature permeability test set-up, the elevated temperature permeability test set-up additionally contains a test fluid heating system (based on copper tubes wound around cartridge heaters as shown on the left-hand side of Figure 16) as well as a flow probe heating system (based on flexible line heaters) as shown on the right-hand side of figure 8 .

Cartridge heaters as used (together with copper tubes wound around them) for fluid heating:

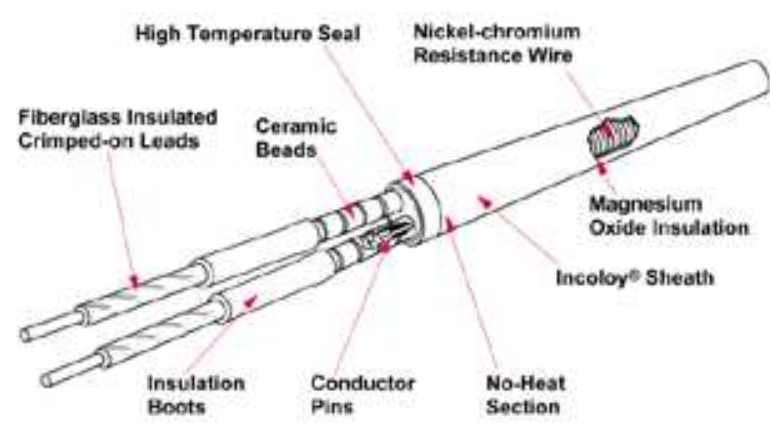

Flow probe holder (made from copper) including flexible line heaters:
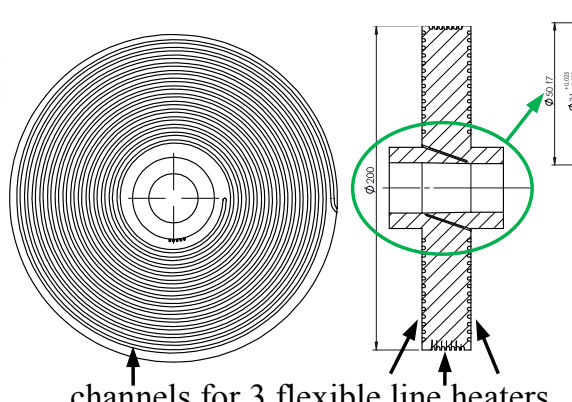

\section{$\frac{100}{20}$}

. 
Before the start of each elevated temperature permeability test, the (closed loop) control units of the fluid heater and the sample heater are set to the intended temperature levels. During the test, a variation of the mass flow rate trough the flow probe and the total pressure level in the flow probe is obtained by a wide variation of the opening levels of control valves situated upstream and downstream of the flow probe as indicated on the left-hand side of Figure 17. As the main test objective is to obtain a large number of stationary values for the mass flow rate, the total pressure level as well as the differential pressure between the inlet and the outlet of the flow probe, pre defined control valve opening setting sequences are used insead of a closed loop control of the valves. A photograph of the complete test set-up is shown on the right-hand side of Figure 17.

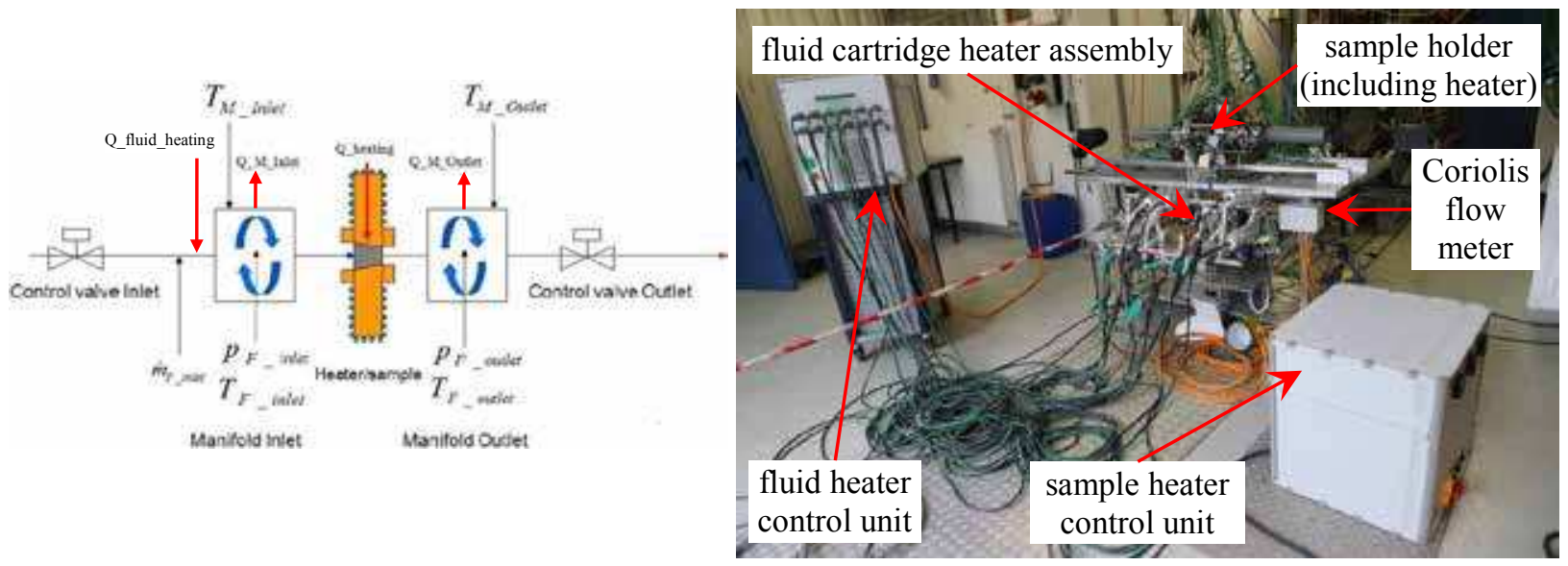

Figure 17 : Flow scheme (left) and photograph (right) of the elevated temperature permeability measurement set-up.

\section{Cooled CMC micro combustion chamber long duration testing}

To evaluated the geometric effect of actual combustion chamber in addition to the material behavior of the CMC in the combustion atmosphere, micro combustion chambers are manufactured using the PTAH-SOCAR technology $6,8,10$

Using the ERBURIG ${ }^{\mathrm{K}}$ test facility of Airbus Group Innovations in Ottobrunn (Germany), the cooled CMC combustion chamber are tested for long duration (hours) instead of minutes ${ }^{6}$. The test set-up is shown in Figure 18. The combustion chamber is encapsulated with a metal housing for gas tightness and cooled using gaseous nitrogen $\left(\mathrm{GN}_{2}\right)$. Further downstream the metal throat is cooled by water.

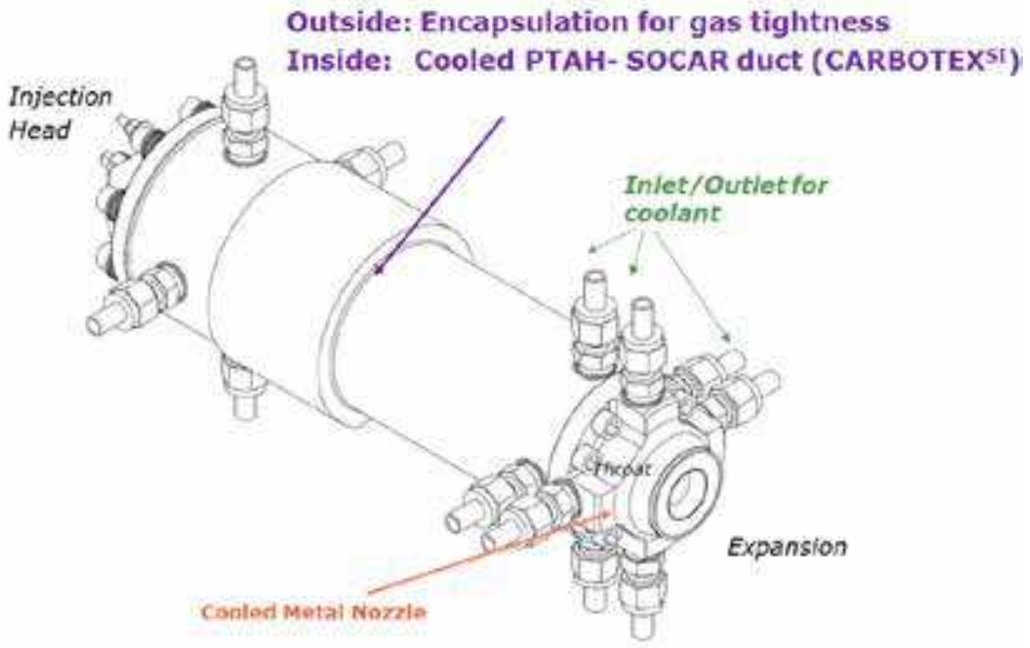

Figure 18: cooled CMC duct for long duration testing in ERBURIG ${ }^{\mathrm{K}}$ test facility at Airbus Group Innovations in Ottobrunn, Germany 


\section{HSS cooled testing in scramjet environment}

Based on the work performed in ATLLAS1 ${ }^{1,3}$ and in current WP3, a generic transpiration cooled metallic panel with hollow sphere core ${ }^{3,9}$ will be tested in the METHYLE test facility ${ }^{7}$.

Many characterizations and computations are made to prepare this test series.

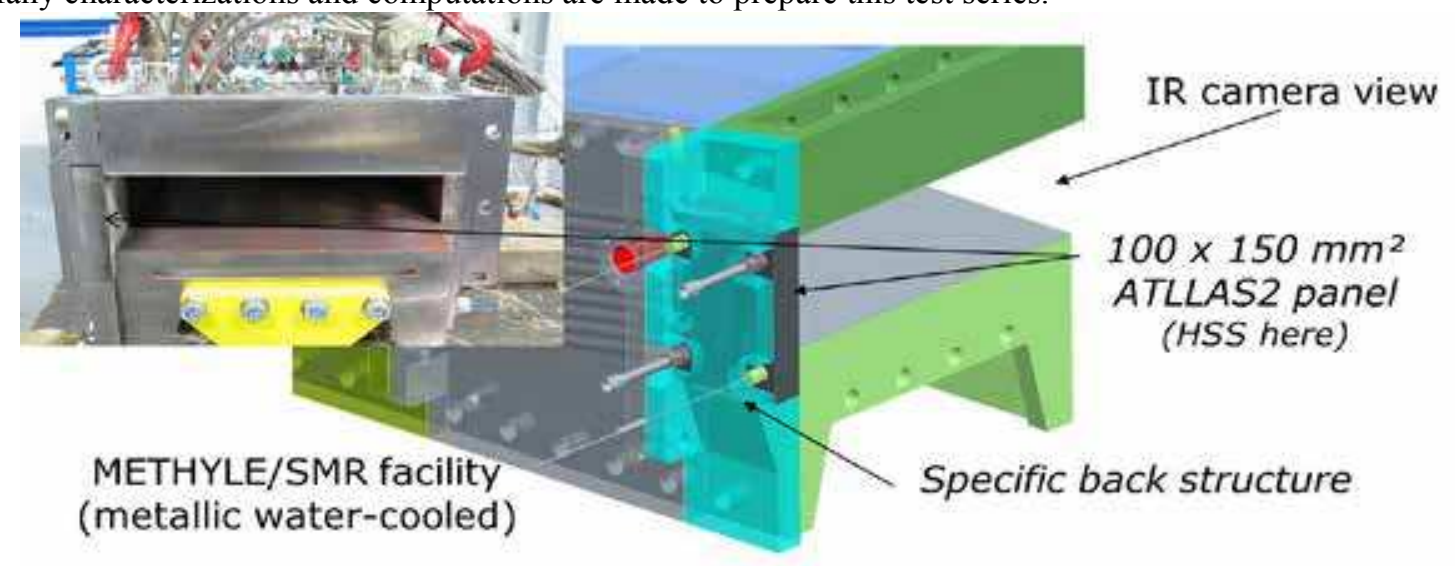

Figure 19 : panel testing at the exit of scramjet in METHYLE test facility

A generic HSS panel was designed and manufactured for cold and hot characterization.
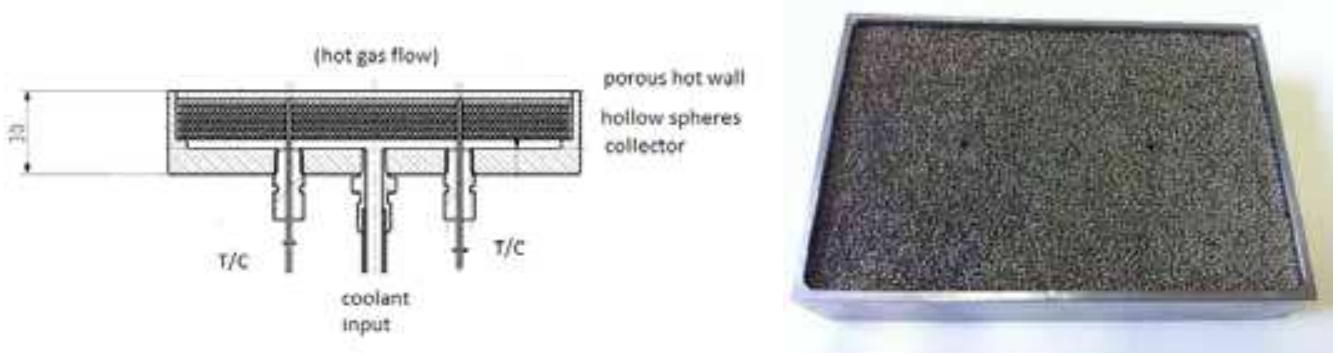

Figure 20: HSS panel to be tested in METHYLE

The HSS panel is composed with a box with thermocouples (T/C) and coolant input and collector at the bottom part. The porous hot wall is in contact with the hot gases, with a low permeability. The hollow sphere core is welded to it and has a higher thickness and a higher permeability. The shell thickness of the hollow spheres (diameter $=2$ $\mathrm{mm}$ ) is around $50 \mu \mathrm{m}$, and the resulting apparent density is $0,6 \mathrm{~g} / \mathrm{cm}^{3}$.

This multifunctional sandwich is then composed fo tow layers of different porous material. The permeabilities of the two porous materials are very dissimilar: around $5.10^{-11} \mathrm{~m} 2$ for the thin porous layer in contact with hot gases, and around 100 times greater the for hollow spheres material, core of the sandwich material.

Before METHYLE hot test, it has been tested in cold and hot conditions with and without coolant.

Cold GN2 calibration was realized at ONERA to check the pressure drop versus mass flow characteristic.

MBDA has realized hot test series without any flow (no coolant, no hot gaz) in unsteady manner under Infra-red lamps facility. This thermal facility is able to heat such a sample during a few seconds under a heat flux of $1 \mathrm{MW} / \mathrm{m}^{2}$. The results (Figure 21) allowed us to document the behaviour of the double layer porous panel and would especially allow to estimate the effective diffusivity with stagnant air inside. 

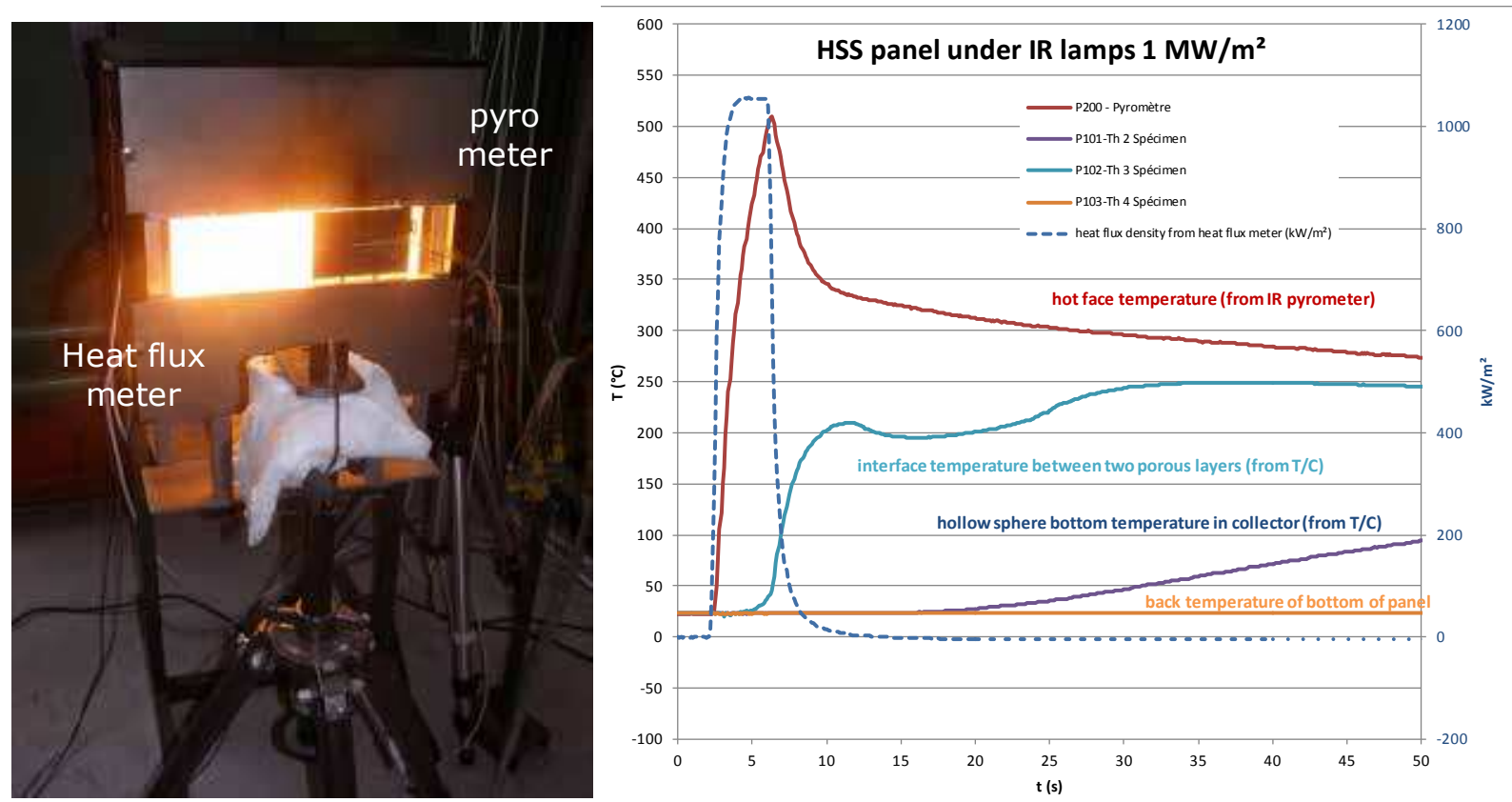

Figure 21. Infra red testing at MBDA of HSS panel

METHYLE test series are planned with and without combustion under Mach 6 flight conditions in second part of 2014.

\section{UHTC and CMC injection struts}

Based on different projects and published results, and on the test facilities capacities, a generic diamond shape injection strut was defined. Different technologies of cooling (convective, transpiration), different materials (UHTC and $\mathrm{CMC}$ ) will be applied to manufacture such samples.

- Generic injection strut whatever the concepts

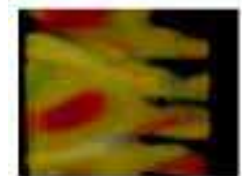

MEOAMNERA
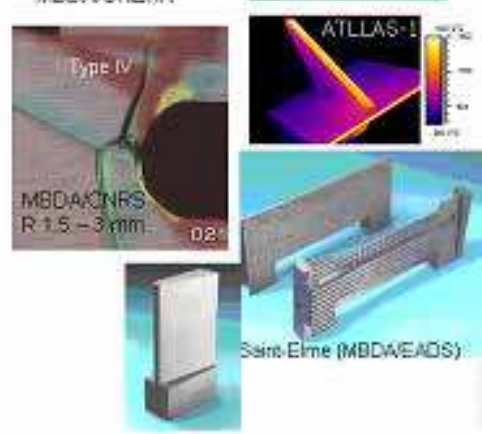

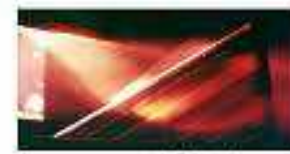

MEOAMMII
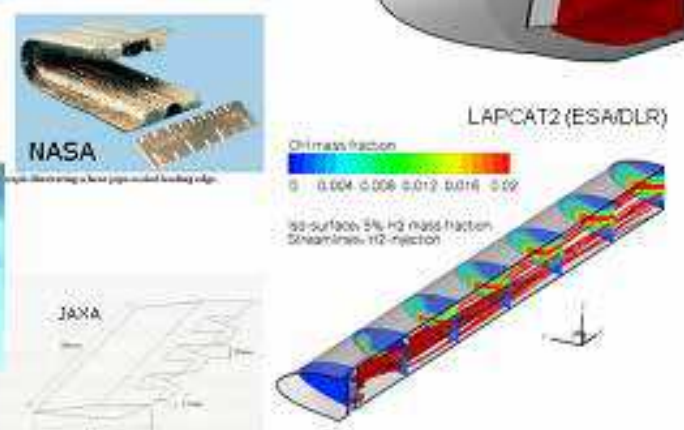

Figure 22 : examples of injection struts taken into account to define the ATLLAS2 generic fin injector 


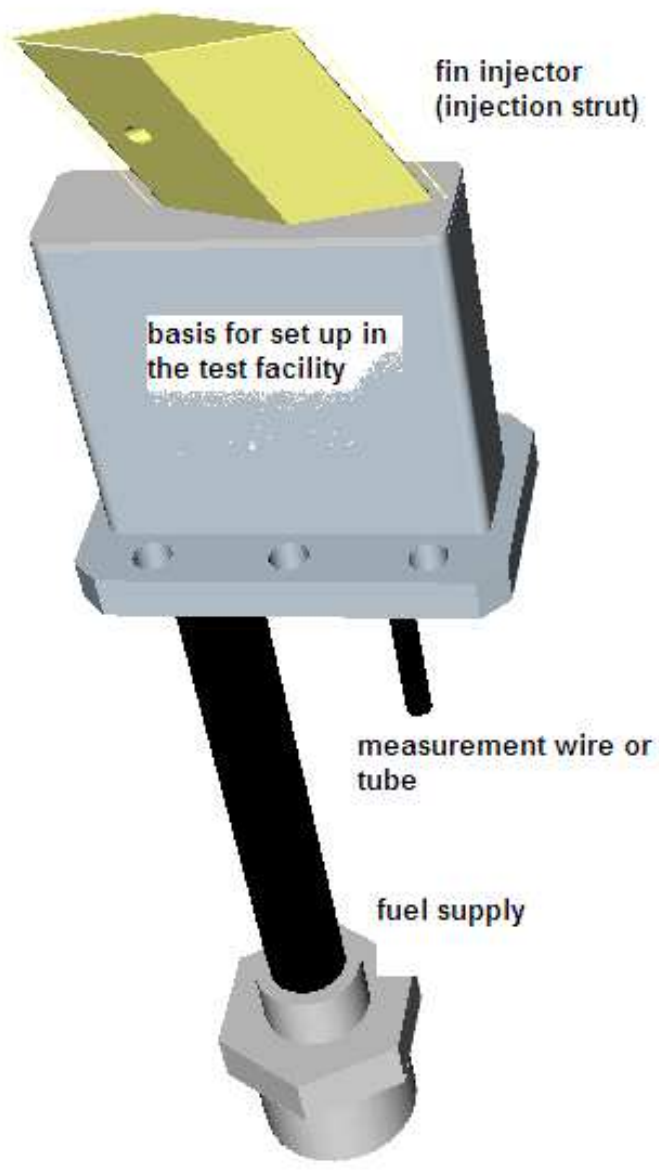

Figure 23 : CAD view of ATLLAS2 injector on its test facility basis

Injectors will be tested in two scramjet ducts, with combustion : in USTUTT academic test facility (one strut of UHTC technology) in Stuttgart and in METHYLE industrial test facility in Bourges (several struts with CMC and UHTC technologies can be tested in the same test and in the same raw in this modular water-cooled chamber).

Concerning the UHTC materials which are studied at ONERA ${ }^{11}$, three compositions based on diborides compounds ${ }^{12}$ have been investigated in the Workpackage 3 where new solutions are developed to deal with external or internal components of the ATLLAS vehicle. The Field Assisted Sintering Technology (or Spark Plasma Sintering) has been selected to manufacture these ceramics and a thorough characterization of basic properties has been carried out on the sintered discs.

An important work has been done on the design of the UHTC injector in order to determine several crucial aspects of this component : external shape, internal design (fuel pipe ...), joining between the different parts (UHTC injector, CMC basis, metallic chamber). Furthermore, some modeling have been carried out to simulate realistic environment (scramjet functioning). Moreover, some machining trials have been done to demonstrate the feasibility of this type of component (WEDM, diamond machining, drilling). 


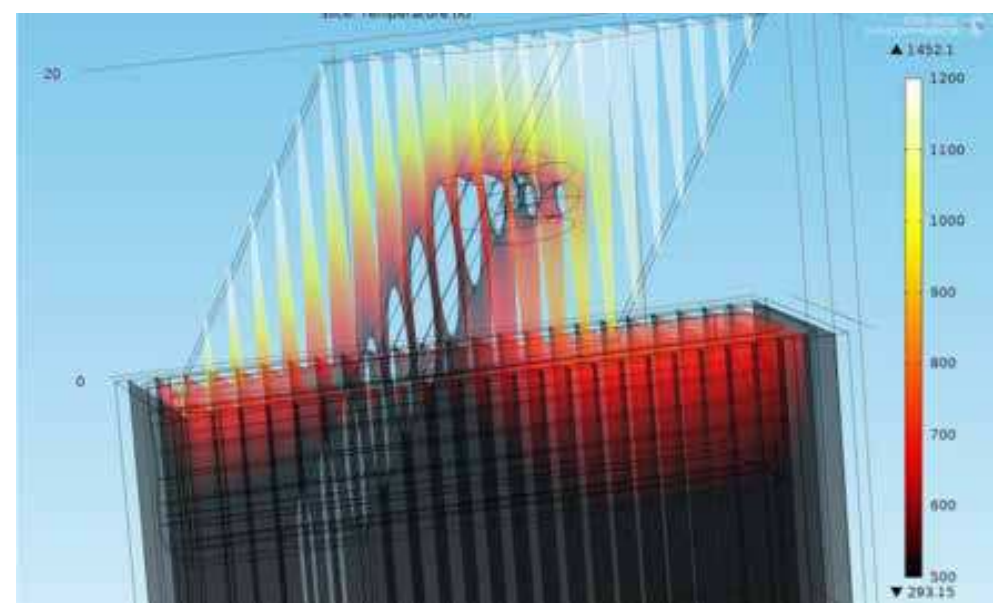

Figure 24 : Assessment of the thermal levels (in K) in the ATLLAS2 injector (during test)

Manufacturing of injectors began with the machining of existing blocks of CMC from DLR or UHTC from ONERA. ONERA checked its capacity to manufacture them from $12 \mathrm{~mm}$ thick UHTC disks of $60 \mathrm{~mm}$ diameter, with the chosen compositions.
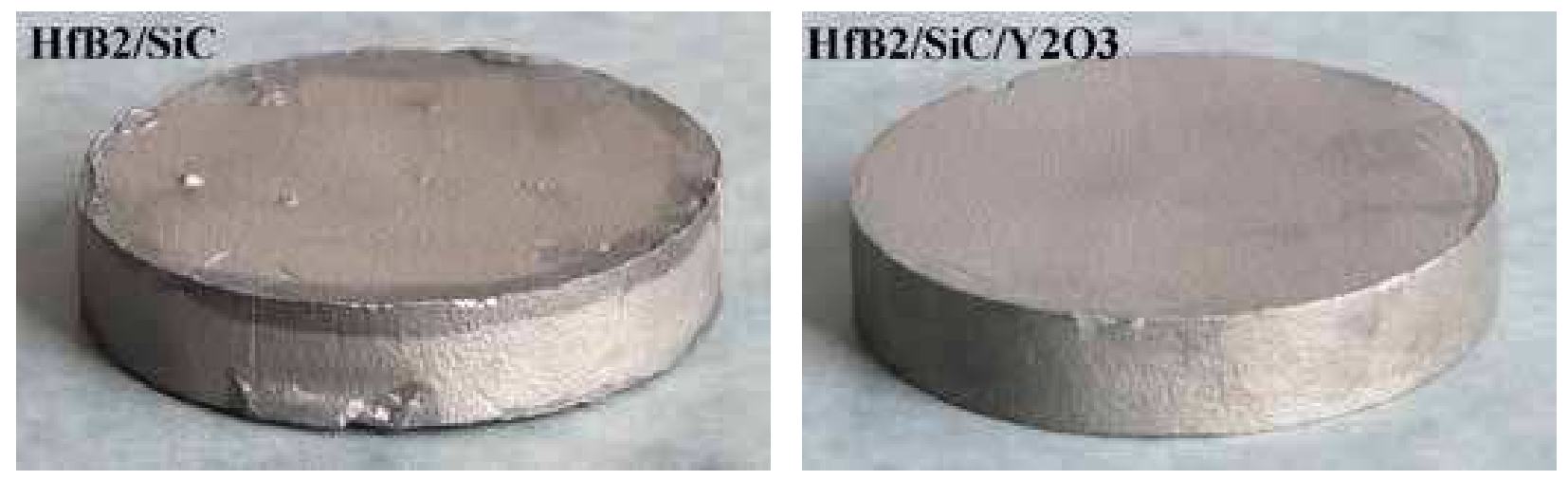

Figure 25. UHTC materials for fin injector machining

Hot tests of these different types of fin injectors are programmed at the end of 2014. They are planned to be fed with $\mathrm{H} 2$ or a mixture of $\mathrm{H} 2$ and $\mathrm{CH} 4$.

VIII.

\section{Conclusion}

The ATLLAS2 program gives the opportunity to investigate at academic level, both in basic and relevant environment, different solutions possibly usable to ensure the long range cruise of a high speed airliner.

Different materials (UTHC, CMC, metallic) and different cooling techniques (radiation, convective, transpiration) are studied. Available numerical or semi-empirical tools are used to prepare the test, to design the different architectures. Test facilities are used from laboratories to industrial environments.

First results in hot conditions are already available but test are going on up to the end of the Research Program, planned in 2015.

\section{Acknowledgments}

This work was performed within the 'Aero-Thermodynamic Loads on Lightweight Advanced Structures II' project investigating high-speed transport. ATLLAS II, coordinated by ESA-ESTEC, is supported by the European Union within the 7th Framework Programme Theme 7 Transport, Contract no.: ACP0-GA-2010-263913. Further info on ATLLAS II can be found on http://www.esa.int/techresources/atllas II. 


\section{References}

${ }^{1}$ Steelant J.: "Achievements obtained on Aero-Thermal Loaded Materials for High-Speed Atmospheric Vehicles within ATLLAS", AIAA-2009-7225, 16th AIAA/DLR/DGLR International Space Planes and Hypersonic Systems and Technologies Conference, Bremen, Germany, October 19th-22nd, 2009.

${ }^{2}$ http://www.esa.int/Our_Activities/Space_Engineering/ATLLAS II__Project_summary

${ }^{3}$ Bouchez M., Dufour E. Benezech L., Cheuret F., Steelant J., Grenard P., Redford J.A., Sandham N.D., Roberts G.T., Passaro A.. Baccarella A., Dalenbring M., Smith J. and Cavagna L. : "Multi-level Coupled Simulations of Cooled Structures in the ATLLAS European Programme", AIAA-2009-7374, 16th AIAA/DLR/DGLR International Space Planes and Hypersonic Systems and Technologies Conference, Bremen, Germany, 19-22 October, 2009

${ }^{4}$ Jacob M., "Heat transfer and flow resistance in cross flow of gases over tube banks," Trans. ASME 59, pp. 384386,1938

${ }^{5}$ Poser R., J. von Wolfersdorf, "Transient liquid crystal thermography in complex internal cooling systems”, VKI Lecture Series 2010-05, Internal Cooling in Turbomachinery, von Karman Institute for Fluid Dynamics, Rhode-Saint-Genèse, Belgium, 2010.

${ }^{6}$ Schmidt-Wimmer, S., Beyer, S., Wigger, F., Quering, K., Bubenheim, K., and Wilhelmi, C. "Evaluation of Ultra High Temperature Ceramics and Coating-Systems for their Application in Orbital and Air-Breathing Propulsion", 18th International Space Planes and Hypersonic Systems and Technologies Conference, Tours, France.

$09 / 2012$

${ }^{7}$ Falempin F. et Minard J.P. . «METHYLE - A new long endurance test facility fordual-mode ramjet technologies. » AIAA-2006-2650, Hypersonic technologies conference, Dayton, USA, Apr. 2008.

${ }^{8}$ Bouchez M., Cahuzac G., Beyer S. : «PTAH-SOCAR fuel-cooled composite materials structure in 2003 ». AIAA2003-6919, Norfolk, USA, Dec. 2003.

${ }^{9}$ Davoine C., Götzfried A., Mercier S., Popoff F., Rafray A., Thomas M. and Marcadon V. : "Metallic hollow sphere structures manufacturing process", Material Research Society Spring meeting, San Fransisco, USA, 13-17 April 2009

${ }^{10}$ Bouchez M., Beyer S. : "PTAH-SOCAR fuel-cooled composite material structure : 2009 status". AIAA-20097353.

${ }^{11}$ Justin J.F., Jankowiak A. "Ultra High temperature Ceramics: Densification, Properties and Thermal Stability"; AerospaceLab, issue 3-November 2011

${ }^{12}$ Fahrenholtz W.G., Hilmas G.E., I. G. Talmy and J. A. Zaykoski "Refractory Diborides of Zirconium and Hafnium”. J. American Ceramic Society 90, 1347-1364, 2007 